\title{
Birefrince Characteristics of an Optical Element
}

\author{
R.Suganya, S. Bharanidharan, R. Sreelatha
}

\begin{abstract}
Phase difference variation in uniaxial crystal is investigated for varying thickness. Using double refraction property and optic axis method leads to the intensity measurement. The periphery example got when a unique (or focalized) shaft experiences an example of birefringent gem between two polarizers contains data which is intrinsic of the crystalline example under examination.
\end{abstract}

Key words: Uniaxial crystal, Phase difference, Intensity and Thickness.

\section{INTRODUCTION}

The device that divides the unpolarized light into two components and discards one is called polarizer. A polarizer does not create transverse vibrations, but merely divides the existing vibrations into two and selects one. Symmetric crystals have the same optical properties in all directions and are optically isotropic. Other crystals are not isotropic, some have a single axis with the same properties in all directions perpendicular to this axis but different properties along these axis .Such crystals are uniaxial and the axis of symmetry is called the optic axis. These crystals will satisfy the double refraction property. calcite, Nicol, Quartz are some examples of uniaxial crystals. [1],[3],[5]

When linearly polarized light is passed through the uniaxial crystal it is split up into two rays. Ordinary ray and extra ordinary ray. These two rays travel with the same velocity of light and index of refraction along the axis. It is called optic axis. If a polarizer and analyzer are placed in crossed position no light is transmitted through the analyzer. If a piece of uniaxial crystal is inserted between the polarizer and analyzer the light from the polarizer is directed along the optic axis of the uniaxial crystal and light is transmitted by the analyzer. The vibration plane has been rotated through an angle equal to the angle through which the analyzer was turned to reextinguish the light. This property that certain substances and crystals have of rotating the plane of vibration

Revised Manuscript Received on July 22, 2019.

R.Suganya Department of Physics, Bharath Institute of Higher Education and Research (BIHER), Chennai -600073.Email:suganya_s_r@yahoo.com

Dr. S. Bharanidharan Department of Physics,

Bharath Institute of Higher Education and Research (BIHER), Chennai -600073.Email:bharani.dhran@gmail.com

Dr. R. Sreelatha Department of Physics, Bharath Institute of Higher Education and Research (BIHER), Chennai

-600073.Email:sreelatha.phy@bharathuniv.ac.in ofpolarized light is called the optical activity.

The light propagating through the crystal may develop a net phase difference between E-components perpendicular and parallel to the crystal optic axis, but the beam remains a singles beam of light. [25],[27],[29]

Theory

The polarizer and analyzer are placed in its maximum intensity positions.

This is achieved by fixing the polarizer at 00 and rotating the rotating the analyzer. At two points maximum intensity positions are noted.Uniaxial crystal is introduced between the polarizer and the analyzer.if it is rotated maximum intensity is obtained at two points. If these two points are joined the optic axis is obtained.Uniaxial crystal will also satisfy the double refraction property. If the transmission axis of the analyzer is placed parallel to that of the polarizer that is along $x$ axis the intensity is $\operatorname{Ix}(\alpha)$. If the transmission axis of the analyzer is placed along the $\mathrm{z}$ axis(i.e) perpendicular to the transmission axis of the polarizer the intensity is $\operatorname{Iz}(\alpha)$. The angle between the optic axis and the transmission axis of the uniaxial crystal is varied and the corresponding intensities are noted. The components of the electric field leaving the crystal parallel and perpendicular to the optic axis are[7],[9],[11]

$$
\begin{aligned}
& \mathrm{E} 11=\mathrm{E} 0 \operatorname{Cos}(\omega \mathrm{t}+\delta) \cos \alpha \\
& \mathrm{E}^{\perp}=\mathrm{E} 0 \operatorname{Cos} \omega \mathrm{t} \operatorname{Sin} \alpha
\end{aligned}
$$

Where E0 is the amplitude of the incident electric field, $\omega$ its angular frequency and $\delta$ the phase difference.

If the transmission axis of the analyzer along the $\mathrm{X}$ axis then the intensity Ix on the analyzer is obtained by taking the time average of the square of Ex.

The Cosine of the phase difference

$\operatorname{Cos} \delta=\ldots$ (Ix)min - (IZ)max

(Ix)min + (IZ)max 


\section{Birefrince characteristics of an optical element}

\section{RESULTS \& DISCUSSION}

Table 1

Intensity transmittance at various angles of $g$

\begin{tabular}{|c|c|c|}
\hline $\begin{array}{r}\alpha \\
\text { (Degrees) }\end{array}$ & $\mathrm{I}_{\mathrm{x}}(\alpha)$ in $\mathrm{Lux}$ & $\mathrm{I}_{4}(\alpha)$ in $\mathrm{Iux}$ \\
\hline 0 & 59 & 24 \\
\hline 10 & 55 & 27 \\
\hline 20 & 45 & 36 \\
\hline 45 & 20 & 57 \\
\hline 80 & 42 & 27 \\
\hline 90 & 52 & 23 \\
\hline 120 & 31 & 39 \\
\hline 180 & 60 & 24 \\
\hline
\end{tabular}

Table 2

\section{Phase difference variation for different thickness}

\begin{tabular}{|l|l|}
\hline No of layers & $\begin{array}{l}\text { Phase difference } \\
(\mathrm{rad})\end{array}$ \\
\hline 1 & 1.99 \\
\hline 2 & 3.98 \\
\hline 3 & 5.97 \\
\hline 4 & 7.96 \\
\hline 5 & 9.95 \\
\hline
\end{tabular}

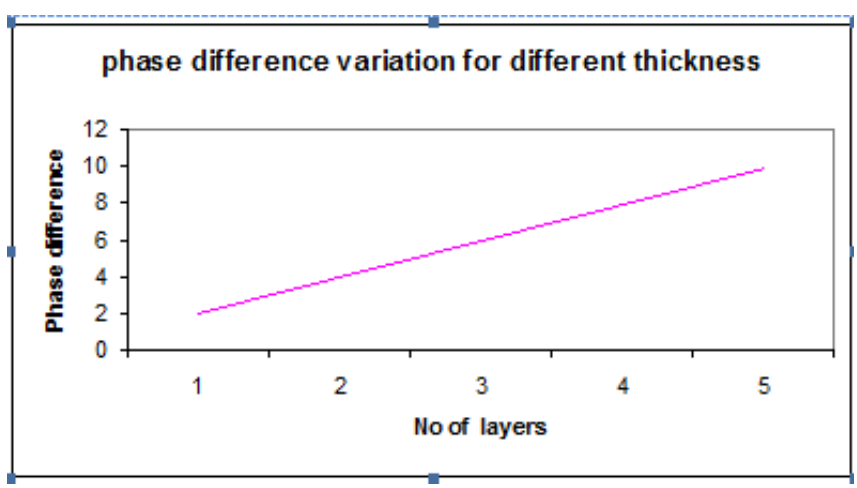

Table 1 shows that for various values of $\alpha$ intensity transmitted through the analyzer is not uniform, there is a random variation in the intensity. At an angle of 45 degree intensity transmitted is high. For various thicknesses the phase difference is calculated and is given in table 2. The graph is plotted for phase difference variation for different thickness, it shows a linear variation between them.

\section{REFERENCES}

1) Nageshwari M., Jayaprakash P., Kumari C.R.T., Vinitha G., Caroline M.L., Growth, spectral, linear and nonlinear optical characteristics of an efficient semiorganic acentric crystal: L-valinium L-valine chloride, 2017, Physica B: Condensed Matter, V-511, PP -1-9,

2) Sangeetha P., Jayaprakash P., Nageshwari M., Rathika Thaya Kumari C., Sudha S., Prakash M., Vinitha G., Lydia Caroline M., Growth and characterization of an efficient new NLO single crystal L-phenylalanine D-methionine for frequency conversion and optoelectronic applications, 2017, Physica B: Condensed Matter, V-525, PP-164-174

3) Peer Mohamed M., Jayaprakash P., Nageshwari M., Rathika Thaya Kumari C., Sangeetha P., Sudha S., Mani G., Lydia Caroline M. Crystal growth, structural, spectral, thermal, linear and nonlinear optical characterization of a new organic nonlinear chiral compound: L-tryptophan-fumaric acid-water (1/1/1) suitable for laser frequency conversion, 2017, Journal of Molecular Structure, V-1141, PP-551-562

4) Jayaprakash P., Sangeetha P., Kumari C.R.T., Caroline M.L., Investigation on the growth, spectral, lifetime, mechanical analysis and third-order nonlinear optical studies of L-methionine admixtured D-mandelic acid single crystal: A promising material for nonlinear optical applications, 2017, Physica B: Condensed Matter, V-518, PP-1-12

5) Nageshwari M., Kumari C.R.T., Vinitha G., Mohamed M.P., Sudha S., Caroline M.L., Crystal growth, structural, spectral, thermal, dielectric, linear and nonlinear optical characteristics of a new organic acentric material: L-Methionine-Succinic acid (2/1), 2018, Journal of Molecular Structure, V-1155, PP-101-109

6) Jayaprakash P., Sangeetha P., Kumari C.R.T., Baskaran I., Caroline M.L., Growth and characterization of 1-asparagine monohydrate admixtured dl-mandelic acid nonlinear optical single crystal, 2017, Journal of Materials Science: Materials in Electronics, V-28, PP-18787-18794

7) Rathika Thaya Kumari C., Nageshwari M., Jayaprakash P., Sangeetha P., Sudha S., Lydia Caroline M., Investigation on growth, optical, thermal, mechanical, dielectric, LDT studies of sulphanilic acid monohydrate: A promising third-order nonlinear optical material, 2017, Journal of Nonlinear Optical Physics and Materials, V-26, I - 2,

8) Thaya Kumari C.R., Nageshwari M., Raman R.G., Caroline M.L., Crystal growth, spectroscopic, DFT computational and third harmonic generation studies of nicotinic acid, 2018, Journal of Molecular Structure, V-1163, PP-137-146

9) Nageshwari M., Kumari C.R.T., Sangeetha P., Vinitha G., Caroline M.L., Third order nonlinear optical, spectral, dielectric, laser damage threshold, and photo luminescence characteristics of an efficacious semiorganic acentric crystal: L-Ornithine monohydrochloride, 2018, Chinese Journal of Physics, V-56, I - 2, PP-502-519

10) Kumari C.R.T., Jayaprakash P., Nageshwari M., Mohamed M.P., Sangeetha P., Caroline M.L., Growth, optical, photoluminescence, dielectric, second and third order nonlinear optical studies of benzoyl valine acentric crystal, 2017, Molecular Crystals and Liquid Crystals, V-658,I - 1, PP-186-197

11) Rathika Thaya Kumari C., Nageshwari M., Sudha S., Lydia Caroline M., Mani G., Influence of uranyl on the growth, linear, laser damage threshold and nonlinear optical studies on potential nonlinear optical single crystal: L-Alanine, 2015, Journal of Chemical and Pharmaceutical Sciences, V-2015-October,PP-166-170,

12) Rathika Thaya Kumari C., The detailed study ontwo dimensional hydrogen atom, 2013, Middle - East Journal of Scientific Research, V-17,I-12, PP-1900-1902

13) Rathika Thaya Kumari C., Theoretical study about the measurement of ultrasonic velocity using different methods, 2013, Middle - East Journal of Scientific Research, V-17, PP-12-

14) Mukunthan A., Rathika Thaya Kumari C., Nageshwari M., Prakash D., The effect of super saturation and crystal growth kinetics of L-arginine per chlorate, 2013, Middle - East Journal of 
Scientific Research, V-17,I-12 PP-1825-1827

15) Sree Latha R., Vijayaraj R., Azhagiya Singam E.R., Chitra K., Subramanian V., 3D-QSAR and Docking Studies on the HEPT Derivatives of HIV-1 Reverse Transcriptase, 2011, Chemical Biology and Drug Design, V-78,I-12, PP-1816-1819

16) Sree Latha R., Vijayaraj R., Padmanabhan J., Azhagiya Singam E.R., Chitra K., Subramanian V., 3D-QSAR studies on the biological activity of juvenile hormone mimetic compounds for Culex pipiens Larvae, 2013, Medicinal Chemistry Research, V-22, I-12,PP-418-426

17) Subashini G.,A simple proof on coloring of dominated special graphs, Indian Journal of Science and Technology,V-7,I-,PP-5-6,Y-2014

18) Ramya N.,On coloring of corona graphs, Indian Journal of Science and Technology,V-7,I-SUPPL2,PP-9-11,Y-2014.

19) Ramya N., On colourings of wheel graph (Wn), Indian Journal of Science and Technology,V-7,I-,PP-72-73,Y-2014.

20) Ramya N., On star chromatic number of $P 3$ (n), Indian Journal of Science and Technology,V-7,I-,PP-7-8,Y-2014.

21) Vijayaragavan S.P.,An investigative expert that's general FBG sensors,International Journal of Mechanical Engineering and Technology,V-8,I-8,PP-1500-1505,Y-2017

22) Vijayaragavan S.P.,Equalization routing protocol for Wi-Fi sensor strategy,International Journal of Mechanical Engineering and Technology,V-8,I-8,PP-1662-1666,Y-2017

23) Karthik B., Kiran Kumar T.V.U., Vijayaragavan P., Bharath Kumaran E.,Design of a digital PLL using 0.35 $\hat{\mathrm{I}}^{1} / 4 \mathrm{~m}$ CMOS technology,Middle - East Journal of Scientific Research,V-18,I-12,PP-1803-1806,Y-2013

24) Kanniga E., Selvaramarathnam K., Sundararajan M.,Kandigital bike operating system,Middle - East Journal of Scientific Research, $\mathrm{V}$

25) Jasmin M., Vigneshwaran T., Beulah Hemalatha S.,Design of power aware on chip embedded memory based FSM encoding in FPGA,International Journal of Applied Engineering Research,V-10,I-2,PP-4487-4496,Y-2015

26) Jasmin M.,Optimization techniques for low power VLSI circuits,Middle - East Journal of Scientific Research,V-20,I-9,PP-1082-1087,Y-2014

27) Jasmin M., Vigneswaran T.,Fuzzy controller for error control of on Chip communication,2017 International Conference on Algorithms, Methodology, Models and Applications in Emerging Technologies, ICAMMAET 2017,V-2017-January,I-,PP-1-5,Y-2017

28) Ramya N., On star chromatic number of P3 (n), Indian Journal of Science and Technology,V-7,I-,PP-7-8,Y-2014.

29) Cauchy Multiplication of Euler Summable series in Ultrametric Fields, PNNVS R.Deepa Commentationes Mathematicae 53 ((1)), 73- 79

30) Kumaravel A., Meetei O.N.,An application of non-uniform cellular automata for efficient cryptography,Indian Journal of Science and Technology,V-6,I-SUPPL5,PP-4560-4566,Y-2013

31) Kumaravel A., Meetei O.N.,An application of non-uniform cellular automata for efficient cryptography,2013 IEEE Conference on Information and Communication Technologies, ICT 2013,V-,I-,PP-1200-1205,Y-2013

32) Kumarave A., Rangarajan K.,Routing alogrithm over semi-regular tessellations,2013 IEEE Conference on Information and Communication Technologies, ICT 2013,V-,I-,PP-1180-1184,Y-2013

33) Gopinath S., Sundararaj M., Elangovan S., Rathakrishnan E.,Mixing characteristics of elliptical and rectangular subsonic jets with swirling co-flow,International Journal of Turbo and Jet Engines, V-32,I-1,PP-73-83,Y-2015

34) Rathika Thaya Kumari C., A brief review on the impacts of tropospheric ozone on biological systems, 2013, Middle - East Journal of Scientific Research, V-17,I-12, PP-1820-1824

35) Mukunthan A., Rathika Thaya Kumari C., Nageshwari M., Prakash D., A brief review on the applications of fluorescent spectroscopy in biomedical diagnosis, 2013, Middle - East Journal of Scientific Research, V-17,I-12, PP-1828-1830

\section{AUTHORS PROFILE}

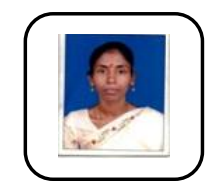

R.Suganya,Assistant professor Department of Civil Engineering, Bharath Institute of Higher Education and Research, Chennai, India

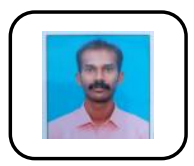

Dr. S. Bharanidharan,Associate professor, Department of Civil Engineering, Bharath Institute of Higher Education and Research, Chennai, India

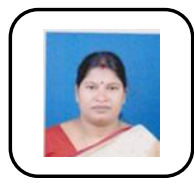

Dr. R. Sreelatha Professor Department of Civil Engineering, Bharath Institute of Higher Education and Research, Chennai, India 